\title{
Review: self help, media based behavioural therapy is effective for behaviour problems in children
}

Montgomery P. Media-based behavioural treatments for behavioural disorders in children. Cochrane Database Syst Rev

2001;(2):CD002206 (latest version 16 February 2001).

\section{QUESTION: Is self help, media based behavioural therapy effective for managing difficult behaviour in children and adolescents?}

\section{Data sources}

Studies were identified by searching electronic databases; scanning reference lists of articles; and contacting authors.

\section{Study selection}

Studies were selected if they were quasi-randomised or randomised controlled trials (RCTs) of self help, media based (eg, audiotape, book, computer manual, videotape, or some combination of these) behavioural therapy for parents of children with behavioural disorders.

\section{Data extraction}

Data were extracted on patients, interventions, and outcomes. Authors were contacted to obtain missing data. The reviewer assessed the quality of study methods.

\section{Main results}

9 studies (7 randomised, 2 quasi-randomised) met the selection criteria. Follow up ranged from 6 weeks to 2.5 years. Sample sizes ranged from 32-160 children. Sleep problems: 2 studies compared 3 groups: written advice alone, written advice given in addition to face to face contact, and a waiting list control. Both studies showed that each treatment was better than no treatment for improving sleep; treatment groups did not differ. Enuresis: 1 study compared 3 groups: filmed presentation of behavioural training, live training, and a waiting list control. The face to face group had better outcomes than the film group (table). The other study compared 3 treatments for enuresis: urine alarm, urine alarm plus instructions for parents to reinforce the child getting up and using the toilet after hearing the alarm, and urine alarm plus instructions for parents to reinforce the child in the morning for a dry night. At immediate and 2.5 year follow up, success rates were highest when parents reinforced the child getting up and using the toilet after hearing the alarm (table). When the results from these 2 studies were pooled, groups did not differ. Attention deficit hyperactivity disorder: 1 small study $(\mathrm{n}=32)$ compared a booklet of behavioural management advice plus methylphenidate with methylphenidate alone, but 10 participants dropped out. Conduct disorder: 1 study compared 4 groups: individually administered videotape modelling, group discussion videotape modelling (1 video/wk), group discussion only, and a waiting list control for $\{10-12$ weeks $\}$ *. All 3 treatment groups showed fewer behaviour problems, more prosocial behaviours, and less spanking than the control group. Another study by the same authors showed that adding 2 hours of therapist time to an individually administered videotape parenting programme enhanced its effectiveness.

\section{Conclusions}

In children with behaviour problems, self help, media based behavioural therapy is more effective than no treatment. Results are inconclusive for comparisons with usual care or when added to drugs.

*Webster-Stratton C, Kolpacoff M, Hollinsworth T. Selfadministered videotape therapy for families with conduct-problem children: comparison with two costeffective treatments and a control group. J Consult Clin Psychol 1988;56:558-66.

\begin{abstract}
Source of funding: National Health Services Executive Anglia and Oxford, UK.
\end{abstract}

For correspondence: Mr P Montgomery, University Section of Child and Adolescent Psychiatry, University of Oxford, Park

Hospital for Children, Old Road, Headington, Oxford OX3 $7 L O, U K$. Fax $+44(0) 1865762$ 358.

A modified version of this abstract appears in Evidence-Based

Nursing.

\section{COMMENTARY}

The review by Montgomery summarises the efficacy of self help media (eg, books, videos) for treating 3 common behavioural disorders in children: nocturnal enuresis, sleep problems, and conduct problems. Behavioural therapies are the most effective treatments for these problems, and many behavioural self help materials for parents have been developed. Although these materials often make bold claims concerning their effectiveness, few have been evaluated in careful scientific study.

Nine studies met the criteria for the review. Most of the studies found that the materials tested had some positive effects. For nocturnal enuresis and sleep problems, brief written materials highlighting how to use behavioural principles applied to the specific problem proved extremely effective.

For conduct problems in young children, a more serious and difficult problem to treat, a 10 week, video based intervention proved moderately effective, although not as effective as a similar length parenting group intervention which also showed the videos as part of the programme. This self administered approach was enhanced further with 2 supplemental sessions with a behavioural professional.

The findings show that media based, self help interventions hold considerable promise for helping parents of children with common behavioural problems. Although most materials available for parents have not been evaluated, some carefully evaluated materials exist and healthcare professionals should consider including these specific materials in their repertoire. The quality of the specific materials is important, as shown by the fact that 2 of the studies reviewed showed that certain materials were substantially less helpful than others, and can even leave parents discouraged. This finding suggests that the media used need to be carefully selected, since not all materials are equally effective.

Ted Taylor, $\mathrm{PhD}$ Oregon Research Institute Eugene, Oregon, USA

Media based, self help behavioural therapy for enuresis $\dagger$

\begin{tabular}{lll|lll}
\hline Outcomes & Comparisons & Event rates & RBR (Cl) & NNH (Cl) \\
\hline Treatment success at 6 weeksł & Film v face to face group & $30 \% v 75 \%$ & $60 \%(34$ to 81) & 3 (2 to 8) \\
\hline Treatment failure at 2.5 years & $\begin{array}{l}\text { UA + written instructions for immediate } \\
\text { reinforcement } v \text { UA only }\end{array}$ & RRR (CI) & NNT (CI) \\
\hline
\end{tabular}

†RBR=relative benefit reduction; UA=urine alarm. Other abbreviations defined in glossary; RRR, RBR, NNT, NNH, and $\mathrm{Cl}$ calculated from data in article. $\neq D$ ata for this outcome supplied by author. 